\title{
A INCLUSÃO DA CRIANÇA COM AUTISMO NA EDUCAÇÃO INFANTIL COMPREENDENDO A SUBJETIVIDADE MATERNA
}

\author{
Questão norteadora: como a mãe de uma criança com diagnóstico recente de autismo configura \\ subjetivamente essa experiência?
}

Com a proposta de romper com a visão essencialmente biomédica das pesquisas sobre a inclusão escolar a criança com diagnóstico de autismo propomos desenvolver o estudo investigativo, tendo como base a Teoria da Subjetividade de González Rey e Mitjáns Martínez (2017) e Epistemologia Qualitativa de González Rey (2017).

A investigação foi desenvolvida com duas mães de crianças com o diagnóstico recente de autismo matriculadas no ensino regular na modalidade Educação Infantil A pesquisa teve como objetivo geral: compreender aspectos de novas organizações configuracionais constituintes da subjetividade da mãe, ante o diagnóstico recente de autismo do seu filho em inclusão na Educação Infantil do ensino regular mobilizados a partir de suas histórias e de suas vivências em seus contextos relacionais - família, escola e sociedade. E objetivos específicos: 1) Identificar nos espaços sociais que a mãe participante da pesquisa atua - família, escola e comunidade - aspectos ligados à compreensão social do autismo pela visão biomédica e tradição cultural como possibilidade de produção de inteligibilidade de processos favorecedores de constituição de diferentes organizações de configuração subjetiva da mãe. 2) Depreender a possível relação entre diferentes organizações de configuração subjetiva emergentes da mãe da criança com diagnóstico do autismo participante da pesquisa e a dinâmica relacional entre a mãe e a escola na inclusão da criança na Educação Infantil. Como resultado o estudo possibilitou compreender que a subjetividade de cada uma das mães participantes da pesquisa como conjuntos de configurações singulares, que de maneira fluída e em recursividade processual, emergem como diferentes organizações configuracionais, embora em algumas situações preservem alguma estabilidade. São organizações de sentidos subjetivos gerados nas experiências emocionais vividas por elas no momento atual imediato ao diagnóstico de autismo dos filhos e ao longo de suas histórias de vida.

Durante o processo de construção interpretativa das informações foi possível depreender que os processos de experiência emocional são indissociáveis da unidade social e individual que a constitui, referendando as proposições da Teoria da Subjetividade de Gonzalez Rey e Mitjáns Martínez (2017) que apontam a unicidade inextrincável entre processos simbólicos e emocionais, os sentidos subjetivos. A produção subjetiva pode ser entendida, portanto como expressão singular do vivido por cada uma das mães em nas relações simultâneas da qualidade de suas vidas psíquicas e qualidade das relações sociais estabelecidas em seus contextos de atuação e aspectos culturais imbricados subjetivamente na sociedade. A singularidade de uma vivência emocional é então multiconstituída, de modo que não se pode apontar uma única causa real para uma produção simbólico-emocional.

Conclusão

Nessa perspectiva as configurações subjetivas têm organização singular para cada indivíduo e em cada momento histórico da sua vida, em processo ininterrupto na vivência da experiência emocional. Assim, pode-se concluir que embora a mãe produza uma subjetividade que pode aparecer no momento atual, essa subjetividade não pode ser deslocada da sua história e da sociedade em que vive. No processo de análise construtivo-interpretativa a geração de sentidos subjetivos, na experiência de maternar o filho firmou-se, portanto, no marco da qualidade das relações estabelecidas pelas mães em diferentes espaços de atuação dessas mulheres - família, sociedade - ao longo de sua história de vida e no momento atual em relação recursiva e tensional entre subjetividade individual e subjetividade social. Tomando então destaque a importância da qualidade das relações interpessoais estabelecidas nos espaços sociais de atuação de cada mãe como favorecedoras de geração de sentidos subjetivos e emergência processual de configurações subjetivas.

\section{REFERENCIAL}

BARROS, C. L. e TRUGILHO, S. M. Mães de crianças com autismo: desafios enfrentados diante do diagnóstico de autismo. / Carolina Leite Barros. Dissertação em Políticas Públicas e Desenvolvimento Local - Escola Superior de Ciências da Santa Casa de Misericórdia de Vitória, EMESCAM, 2016.

GONZÁLEZ REY. Sujeito e subjetividade: uma aproximação histórico-cultural. São Paulo: Thomson, 2003. 
Subjetividade, complexidade e pesquisa em psicologia. In: Subjetividade, complexidade e pesquisa em psicologia. Pioneira Thomson Learning, 2005. ${ }^{a}$

Vozes, 2012a.

O social na psicologia e a psicologia social: a emergência do sujeito. Petrópolis:

Pesquisa Qualitativa e Subjetividade, os processos da construção de informação.

Editora CENGAGE Learning. São Paulo. 2017

Ideias e Modelos teóricos, na Pesquisa Construtivo-Interpretativa. In: MARTÍNEZ MITJÁNS et al. (org.). Subjetividade Contemporânea, discussões epistemológicas e metodológicas. Editora Alínea. S. P. 2014.

e MITJÁNZ MARTÍNEZ, A. (2015). Una epistemologia para ele estúdio de lá subjetividade: Sus implicações metodológicas. Psicoperspectivas, 15(1), 5-16. dói: 10.5027/PSICOPERSPECTIVAS-VOL15- ISSUE1-FULLTEXT-667

Alínea. 2017. SP.

e MITJÁNS MARTÍNEZ, a. Subjetividade - teoria, epistemologia e método. Editora

GRINKER, Roy Richard. 2010. Autismo: um mundo obscuro e conturbado. São Paulo: Larousse do Brasil.

ORRÚ, S. E. Autismo, linguagem e educação. 2. ed. Rio de Janeiro: Wake, 2012.

Aprendizagens Com Autismo: aprendizagens por eixos de interesse em espaços excludentes. Editora Vozes. Petrópolis. RJ - 2016 